\title{
LAS NUEVAS PROPUESTAS INTERPRETATIVAS DEL TRIBUNAL EUROPEO DE DERECHOS HUMANOS SOBRE EL CONTROL DEL USO LABORAL DE LA TECNOLOGÍA DE LA EMPRESA: BARBULECU Y LÓPEZ RIBALDA
}

\author{
THE NEW INTERPRETATIVE PROPOSALS \\ OF THE EUROPEAN COURT OF HUMAN RIGHTS \\ ON THE CONTROL OF THE LABOR USE OF THE COMPANY'S \\ TECHNOLOGY: BARBULECU AND LÓPEZ RIBALDA
}

\author{
Carlota Ma Ruiz GonzÁlez \\ Doctor en Derecho del Trabajo y de la Seguridad Social \\ Profesor Sustituto Universidad de Extremadura
}

Recibido: 17.05.2018 / Aceptado: 06.06.2017

DOI: https://doi.org/10.20318/cdt.2018.4413

\begin{abstract}
Resumen: El control empresarial del uso de los medios informáticos de la empresa y, en especial, de los mensajes que los trabajadores intercambian a través de estos medios, ha sido un tema polémico que, en España, parecía ya parcialmente resuelto por la doctrina constitucional y jurisprudencial. Pero las recientes STEDH establecen nuevos criterios necesitados de análisis por los cambios importantes que pueden provocar en nuestro sistema. Este trabajo comienza exponiendo la situación anterior a esas sentencias, para después analizar los tres últimos pronunciamientos al respecto del TEDH. El trabajo termina explicando las consecuencias que han tenido en el sistema español.

Palabras clave: Tribunal Europeo de Derechos Humanos, control del empleador, videovigilancia, proporcionalidad, información, derechos fundamentales, derecho a la intimidad, uso de los recursos tecnológicos de la empresa, derecho al secreto de las comunicaciones.
\end{abstract}

\begin{abstract}
The corporate supervisión of workers use of technological resources and, especially the messages swapped throw them, has been a controversial matter that seemed partially solved by the constitutional and jurisprudential doctrine. But the recent "Judgment of the European Court of Human Rights" establishes new criteria that implies a big change in our system, and they have to be analysed. This research analyses the situation before and last three judgements of the European Court of Human Rights. The article ends up explaining the consequences that have had on the Spanish system.
\end{abstract}

Keywords: European Court of Human Rights, employer's control, video surveillance, proportionality, information, fundamental rights, rignt to privacy, use of internet and electronic communications in the workplace, secrecy of communications.

Sumario: I. Introducción. II. La situación anterior a Barbulescu y López Ribalda en la doctrina del TS y del TC: un equilibrio en la línea de un reconocimiento limitado de la facultad empresarial de vigilancia y control. III. ¿Existe un posible cambio interpretativo impuesto por el TEDH en sus sentencias de 12 de enero de 2016 y 5 de septiembre de 2017 (Caso Barbulescu contra Rumania)?. 
1. Antecedentes. 2. Propuestas jurídicas de la primera de las STEDH. 3. Propuestas jurídicas de la segunda de las STEDH. 4. Conclusiones. IV. El más reciente de los pronunciamientos del TEDH en relación al control tecnológico del empresario: Caso López Ribalda y otras contra España. 1. Antecedentes. 2. Valoración jurídica del Tribunal sobre el asunto. 3. Conclusiones. IV. Transcendencia interna de las recientes sentencias.

\section{Introducción}

1.Resulta obvio, hoy en día, que las tecnologías de la información y la comunicación se encuentran prácticamente instaladas en la organización empresarial, presentando un papel destacable en las relaciones laborales. Pese a ello, y más allá de las previsiones incluidas en algunos convenios colectivos, no existe normativa específica que regule su uso en el ámbito laboral, dando lugar a un vacío regulador que dificulta la delicada delimitación entre potestad de vigilancia y control empresarial, y derechos fundamentales del trabajador.

2.En este sentido, establece la doctrina del Tribunal Supremo en su sentencia de 26 de septiembre de 2007 (RJ 2007/7514) que la potestad empresarial de controlar el uso adecuado de las tecnologías, puestas a disposición de los trabajadores, se basa en el art. 20.3 del Estatuto de los Trabajadores (en adelante, ET), que literalmente expresa "el empresario podrá adoptar las medidas que estime más oportunas de vigilancia y control para verificar el cumplimiento por el trabajador de sus obligaciones y deberes laborales, guardando en su adopción y aplicación la consideración debida a su dignidad humana y teniendo en cuenta la capacidad real de los trabajadores disminuidos, en su caso."

3.Como podrá apreciarse de la lectura de este artículo, nada establece el mismo en cuanto a la implantación de las tecnologías en dicho ámbito laboral, reconduciéndose la cuestión a dos vertientes muy genéricas: la posibilidad de vigilar y controlar la actividad laboral aparentemente mediante cualquier mecanismo y el derecho de los trabajadores a la intimidad y a la protección de datos, así como el secreto de las comunicaciones que pueden resultar afectados y vulnerados si se someten a limitaciones injustificadas, desproporcionadas o carentes de habilitación legal.

4.Esta falta de precisión normativa parece en parte entendible, pues la redacción del artículo procede del originario ET de 1980, donde en absoluto se pensaba en el masivo uso que dichos adelantos tendrían actualmente ${ }^{1}$, siendo suplida tal imprecisión por la jurisprudencia interpretativa que al respecto se ha expresado por las distintas instancias jurisprudenciales ${ }^{2}$.

5. En este punto, recientemente, el Tribunal Europeo de Derechos Humanos (en adelante, TEDH) ha dictado tres pronunciamientos que merecen prestar cierta atención por los posibles cambios de criterios o avances que pueden venir a proponer en la regulación de las tecnologías en la empresa. A ellos se dedica este comentario. No obstante, antes de proceder a su análisis, es preciso contextualizar la problemática del uso de las tecnologías en la empresa, desde la perspectiva de la afectación a los derechos fundamentales, e identificar donde se sitúa la regulación extralegal de la cuestión.

\footnotetext{
${ }^{1}$ Esta es la opinión de Sáez Lara para la que las características de estos nuevos medios de vigilancia implican un cambio cualitativo del poder de control empresarial, que resulta difícilmente incardinable en el citado precepto estatutario, pensado para una realidad distinta. En C. SÁEz LARA: «Derechos fundamentales de los trabajadores y poderes de control del empleador a través de las tecnologías de la información y las comunicaciones», Temas Laborales (Revista Andaluza de Trabajo y Bienestar Social), núm. 138, 2017, p. 188.

2 En este sentido se llega a afirmar que en la regulación de las tecnologías de la información y la comunicación, el Derecho del trabajo es básicamente un derecho jurisprudencial, pues la doctrina general sobre el uso y control de estos medios en la empresa se ha construido principalmente a partir de pronunciamientos judiciales. Ma . E. CuAdros GarRIDO: «Mensajería instantánea y la STEDH de 5 de septiembre de 2017», Aranzadi Doctrinal, núm. 11, 2017, p. 2. En similares palabras también se manifestaban con anterioridad J.L. Monereo Pérez y B.M. LóPEZ Insua: «El control empresarial del correo electrónico tras la STC 170/2013 (RTC 2013,170)», Aranzadi Social, núm. 11, 2014.
} 
6. Comenzando por los derechos fundamentales, cabe afirmar que gozan de un tratamiento privilegiado en nuestro Ordenamiento Jurídico. Pese a ello, esto no les convierte en concesiones constitucionales intocable frente a cualquier injerencia ya que, como señaló el Tribunal Constitucional en Sentencia 88/1985, 19 de junio (RTC 1985/88) pueden ceder ante otros intereses constitucionales -como la libertad de empresa (art. 38 Constitución Española) - en la medida en que no se vea afectado su contenido esencial. Siendo, por tanto, los órganos judiciales los encargados de preservar el necesario equilibrio entre las obligaciones del trabajador derivadas del contrato de trabajo y el ámbito de sus derechos y libertades constitucionales ${ }^{3}$.

7. En el ámbito laboral, precisamente, constituye una manifestación del citado art. 38 de la Constitución, el ejercicio del poder de dirección del empresario, el cual incluye entre otras facultades la de adoptar las medidas que estime más oportunas de vigilancia y control para verificar el cumplimiento del trabajador de sus obligaciones laborales, lo que podrá legitimar una bajada de la intensidad de disfrute por éste último de determinados derechos fundamentales ${ }^{4}$.

8. La intensidad de la bajada es lo que constituye el objeto de la mayoría de las controversias jurídicas planteadas ante los distintos tribunales, pues resulta muy difícil determinar el punto intermedio entre derechos constitucionales y aplicaciones, profesionales y personales, que ofrecen estos adelantos tecnológicos, respecto de los cuales no debe olvidarse, como muy acertadamente advierte SÁEZ LARA $^{5}$, que no sólo son instrumentos de trabajo sino herramientas de comunicación y espacios virtuales en los que el trabajador puede disponer de cierta esfera de privacidad legítima.

9. Para dar respuesta a esta cuestión, los tribunales se han venido apoyando en las nociones de "expectativa razonable de intimidad", acogida tanto por el TEDH ${ }^{6}$ como por los tribunales españoles $7, y$ la denominada por la STC 241/2012, de 17 de diciembre (RTC 2012/241) como "expectativa razonable de confidencialidad". La aplicación de estas premisas permite determinar, de forma casuística, el nivel y alcance de protección que merecen los derechos a la intimidad y al secreto de las comunicaciones de cada trabajador, en su proyección laboral, cuando interactúan con el uso de las tecnologías en la empresa. De modo, que dichas expectativas decaerán cuando el empresario prohíba a sus trabajadores, parcial o totalmente, el uso para fines personales de las tecnologías puestas a su disposición, informando de la posible monitorización, y siendo en este marco, totalmente acorde con el respeto a los derechos en conflicto, el ejercicio de la facultad de controlar los accesos y usos que de la tecnología realicen los trabajadores.

10. Por último, y como complemento de las anteriores expectativas, el Tribunal Constitucional (Sentencia 98/2000, de 10 de abril) propone, como mecanismo para valorar la constitucionalidad de la medida empresarial restrictiva de derechos fundamentales, la superación del test de proporcionalidad ${ }^{8}$, el cual implica el cumplimiento de los siguientes tres condicionantes:

\footnotetext{
3 Por todas, Sentencias del Tribunal Constitucional 213/2002, de 11 de noviembre (RTC 2002/2013); 20/2002, de 28 de enero (RTC 2002/20); y, 151/2004, de 20 de septiembre (RTC 2004/151).

${ }^{4}$ Una interpretación aún más extensa del contenido del art. 20 ET es la defendida por Montoya Melgar que incluye también dentro de este concepto al ius variandi (artículo 39 ET); movilidad geográfica (artículo 40 ET); modificaciones sustanciales de las condiciones de trabajo (artículo 41 TRET); despido por causas objetivas (artículo 52 ET); suspensiones y extinciones por causas económicas, técnicas, organizativas o de producción (artículos 47, 51 y 52.c) ET); y despidos por causas objetivas (artículo 52 ET). A. Montoya Melgar: «El Poder de Dirección del Empresario en las Estructuras Empresariales Complejas». Revista del Ministerio de Trabajo y Asuntos Sociales, núm. 48, 2004, p. 135.

Un análisis más extenso sobre la actualización y conjugación del poder de dirección y vigilancia empresarial del art. 20 ET con los adelantos tecnológicos puede verse en C. SÁnchez-Rodas NAVARRO, «Poderes directivos y nuevas tecnologías», Temas Laborales (Revista Andaluza de Trabajo y Bienestar Social), núm. 138, 2017, p. 163 y ss.

5 C. SÁez LARA: «Derechos fundamentales de los trabajadores y poderes de control...», ob.cit., p. 190.

6 Sentencias del Tribunal Europeo de Derechos Humanos, de 25 de junio de 1997 (caso Halford) y, de 3 de abril de 2007 (caso Copland).

7 Sentencia del Tribunal Supremo, de 26 de septiembre de 2007 (RJ 2007/7514).

${ }^{8}$ Un análisis del principio también puede verse en las Sentencias del Tribunal Constitucional 66/1995, de 8 de mayo (RTC 1995/66); 55/1996, de 28 de marzo (RTC 1996/55); 207/1996, de 16 de diciembre (RTC 1996/207); y 37/1998, de 17 de febrero (RTC 1998/37).
} 
- Juicio de idoneidad: si tal medida es susceptible de conseguir el objetivo propuesto

- Juicio de necesidad: si además es necesaria, en el sentido de que no exista otra medida más moderada para la consecución de tal propósito con igual eficacia, y

- Juicio de la proporcionalidad en sentido estricto: si la misma es ponderada o equilibrada, por derivarse de ella más beneficios o ventajas para el interés general que perjuicios sobre otros bienes o valores en conflicto.

11. Adicionalmente se exige por la doctrina que la medida restrictiva de derechos esté suficientemente justificada, lo que significa que la decisión empresarial de control no podrá ser arbitraria o caprichosa, sino que la misma debe resultar suficientemente motivada desde un punto de vista objetivo 9 .

12. Estos son, en definitiva, los parámetros interpretativos que han venido siendo manejados por la jurisprudencia española vemos a continuación, antes de analizar los pronunciamientos europeos, como se vienen conjugando en el territorio español.

\section{La situación anterior a Barbulescu y López Ribalda en la doctrina del TS y del TC: un equili- brio en la línea de un reconocimiento limitado de la facultad empresarial de vigilancia y control}

13. Con anterioridad a los últimos pronunciamientos del TEDH, la situación en España en materia de control empresarial del uso del ordenador y correo electrónico, que es lo que aquí nos interesa, venía siendo complicada por varias razones.

14. En primer lugar, porque como afirma Desdentado Bonete y Desdentado Daroca ${ }^{10}$ la prestación de trabajo que se trata de controlar en estos supuestos no es una realidad que se manifiesta externamente como sucede con la que captan las técnicas ordinarias de reproducción de la imagen y del sonido, sino que es algo interno, que no se expone al exterior y que no es observable directamente sin entrar en el instrumento productivo que lo contiene.

15. En segundo lugar, porque junto con el derecho a la intimidad también puede verse afectado el derecho al secreto de las comunicaciones, que las protege frente a intromisiones de terceros, así como su tratamiento y almacenamiento por cualquier medio, y

16. En tercer lugar, porque en ese control puede estar implicado un tercero ajeno al ámbito laboral, el cual ni se encuentra vinculado por las obligaciones laborales que surgen con la formalización del contrato de trabajo, ni menos aún tiene que soportar el ejercicio por el empresario de sus poderes de vigilancia y control.

17. Estos condicionantes han hecho que durante muchos años la doctrina de suplicación no fuera uniforme, considerando algunas sentencias que el control empresarial del ordenador era lícito al ser una herramienta de trabajo ${ }^{11}$. Otras, por su parte, añadían a la anterior permisibilidad la necesidad de una advertencia previa ${ }^{12}$. Por otra parte, algunas resoluciones consideraban aplicables las garantías

\footnotetext{
9 Una interpretación sobre la justificación puede verse en Ma. B. CARDONA RUBERT, Informática y contrato de trabajo, Valencia, Tirant lo Blanch, 1999, p. 67.

10 A. Desdentado Bonete y E. Desdentado Daroca:, «La segunda sentencia del Tribunal Europeo de Derechos Humanos en el caso Barbulescu y sus consecuencias sobre el control del uso laboral del ordenador», Información Laboral, núm. 1, 2018, p. 2.

11 SSTSJ de Cataluña, de 5 de julio de 2000 (Rec. 1718/2000); de 10 de octubre de 2006 (Rec. 106/2006); y, Andalucía (Sevilla), de 11 de enero de 2008 (Rec. 1315/2007).

12 SSTSJ de Cataluña, de 11 de marzo de 2004 (Rec. 98/2003); Comunidad Valenciana, de 19 de julio de 2005 (Rec. 1343/2005), y de 28 de septiembre de 2010 (Rec. 231/2009).
} 
previstas en el art. 18 ET para el registro de la persona del trabajador y sus efectos personales ${ }^{13}$. Y, finalmente, cuestionando los fundamentos del control empresarial, otras resoluciones negaban la licitud de una prohibición absoluta de uso personal, defendiendo la existencia de un derecho de los trabajadores a comunicarse en el ámbito de la empresa ${ }^{14}$.

18. Frente a esta disparidad de criterios entre los diversos TSJ españoles, la unificación parece se alcanzó, o por lo menos se recondujo a opiniones y visiones más próximas, tras tres STS de 26 de septiembre de 2007 (RJ 2007/7514), de 8 de marzo de 2011 (RJ 2011/932) y de 6 de octubre de 2011 (RJ 2011/7699). En estas sentencias se establecía una doctrina que parte de un principio general respecto al ordenador de trabajo, afirmando "que se trata de medios que son propiedad de la empresa y que ésta facilita al trabajador para utilizarlos en cumplimiento de la prestación laboral, por lo que esa utilización queda dentro del ámbito de poder de vigilancia del empresario, que, como precisa el artículo 20.3 del Estatuto de los Trabajadores, implica que éste "podrá adoptar las medidas que estime más oportunas de vigilancia y control para verificar el cumplimiento por el trabajador de sus obligaciones y deberes laborales»" (STS de 26 de septiembre de 2007).

19. Partiendo de este principio, la Sala IV del Supremo consideró que el art 18 ET "no es aplicable al control por el empresario de los medios informáticos que se facilitan a los trabajadores para la ejecución de la prestación laboral", pues el supuesto que recoge la norma nada tiene que ver con los registros de los medios informáticos de trabajo.

20. Asimismo, añadió el Tribunal que hay que tener en cuenta que existe un habito social generalizado de tolerancia con ciertos usos personales moderados de los medios informáticos y de comunicación facilitados por la empresa a los trabajadores, lo cual genera una expectativa también general de confidencialidad en el uso de aquellos que no puede ser desconocida, aunque tampoco convertirse en un impedimento permanente del control empresarial, porque el trabajador aun teniendo el derecho al respeto de su intimidad, no puede imponer ese respeto cuando utiliza un medio proporcionado por la empresa en contra de las instrucciones establecidas. Es por ello, que concluirá necesario no sólo la necesidad de establecer reglas de uso de la tecnología en la empresa, sino también el informar a los trabajadores sobre los controles que van a llevarse a cabo para verificar el cumplimiento de esas reglas.

21. Pocos meses después de estos pronunciamientos también se manifestó el Tribunal Constitucional, en dos sentencias 241/2012, 17 de diciembre (RTC 212/241) y 170/2013, de 7 de octubre (RTC 2013/170), las cuales no sólo vinieron a consolidar la doctrina unificada del Supremo, sobre las facultades empresariales para regular el uso de los medios informáticos de la empresa, sino que además introdujo la técnica de la ponderación como medida para la resolución de un conflicto entre derechos constitucionales.

\section{III. ¿Existe un posible cambio de criterio interpretativo impuesto por el TEDH en sus sentencias de 12 de enero de 2016 y 5 de septiembre de 2017 (Caso Barbulescu contra Rumania)?}

22. Sobre el caso Barbulescu, el TEDH se ha pronunciado en dos sentencias que se dictaron en las actuaciones iniciadas por la demanda 61496/2008. En ellas se juzga la petición de un ciudadano Rumano (Sr. Bogdan Mihai barbulescu, en adelante Sr. Barbulescu o demandante), que fue despedido por haber hecho uso personal del servicio de mensajería electrónica instalada en su ordenador con fines exclusivamente profesionales.

13 SSTSJ de Málaga, de 25 de febrero de 2000 (Rec. 2207/1999); Madrid, de 13 de noviembre de 2001 (Rec. 3885/2001), de 4 de diciembre de 2002 (Rec. 4976/2002) y, de 5 de noviembre de 2009 (Rec. 4747/2008); y, Cantabria, de 20 de febrero de 2004 (Rec. 47/2004).

14 STSJ de País Vasco, de 6 de noviembre de 2007 (Rec. 2055/2007). 
23. Ante esta decisión, el trabajador insto la nulidad de su despido alegando que la conducta empresarial había sido constitutiva de una vulneración del derecho a la correspondencia privada, reconocido por el art. 28 de la Constitución rumana, cuestión que no fue admitida por el Tribunal, que procedió a confirmar la decisión empresarial por entender que la única manera que tenía el empresario de comprobar la veracidad de las alegaciones del trabajador, según las cuales había utilizado Yahoo Messenger exclusivamente para fines profesionales, era demostrar el contenido de las comunicaciones.

24. Asimismo, considera el Tribunal que el derecho a controlar el uso que hacen los empleados de internet en el trabajo nace del derecho empresarial a controlar la forma en la que se realizan las tareas profesionales. También, en la medida en que la empresa había despedido recientemente a un trabajador por circunstancias similares y que pocos días antes de que se produjeran los hechos que motivaron el despido del Sr. Barbulescu se había distribuido una comunicación empresarial que avisaba de que la actividad de los empleados estaba siendo vigilada, el tribunal de instancia entendió que no se puede reprochar falta de transparencia en la actuación empresarial.

25. Ello le lleva a concluir, en consecuencia, que el uso para asuntos particulares de la cuenta de correo profesional constituía una falta de disciplina conforme al art. 263.2 del Código de Trabajo Rumano, considerando en consecuencia la conducta como una violación de las disposiciones del reglamento interno de la empresa que prohibían dicho uso.

26. Acto seguido, el demandante interpuso recurso contra esta sentencia ante el Tribunal de Apelación de Bucarest, el cual mediante resolución de 17 de junio de 2008 consideró "ajustado a derecho que la jurisdicción en primera instancia declarara que internet es un instrumento que el empleador pone a disposición del empleado para su utilización con fines profesionales y que el empleador está en su derecho de establecer las reglas de utilización de dicho instrumento, estableciendo prohibiciones y adoptando disposiciones que deben ser respetadas por los empleados en su lugar de trabajo...", del mismo modo, continuaba concluyendo, que la empresa que ha realizado una inversión tecnológica en el centro de trabajo está en su derecho de vigilar la utilización que se hace de internet desde el lugar de trabajo, y el empleado que trasgreda esas reglas del empleador cometerá una falta disciplinaria que puede llevar consigo una sanción y en especial, la más grave de las sanciones.

27. Ante esta nueva inadmisión de su petición el Sr. Barbulescu interpuso recurso ante el TEDH, siendo atribuido su conocimiento a la Sección Cuarta, que declaró por unanimidad, salvo un voto ${ }^{15}$, ajustado a derecho los precedentes pronunciamientos entiendo, por tanto, que no existía nada que indicase que las autoridades nacionales no lograran alcanzar un equilibrio justo entre el derecho del demandante al respeto a la vida privada y los intereses del empleador (Sentencia de 12 de enero de 2016). Acto seguido, el día 12 de abril de 2016 el Sr. Barbulescu solicita la remisión del asunto a la Gran Sala ${ }^{16}$, que dicta

15 La sentencia va a acompañada de un voto particular firmado por el juez Pinto de Alburquerque, en el cual el magistrado afirma que el derecho a la libertad de expresión incluye el derecho al uso de internet y que el acceso a internet debe ser considerado como un derecho humano. Partiendo de esta idea, el voto rechaza que la empresa pueda prohibir de forma general a sus empleados el uso de internet y considera inadmisible "una política de control general, automático y continuo" sobre dicho uso. La aplicación de una política de uso de internet en la empresa debería estar sometida a los principios de necesidad y proporcionalidad, debiendo optar la empresa siempre por los medios de control menos invasivos. Además, los trabajadores "deberian ser advertidos de la existencia de una politica de uso de internet en el centro de trabajo", advertencia que tiene que incluir "el propósito de control, su extensión, los medios técnicos utilizados y el horario en que se va a producir". La notificación tendría que hacerse personalmente a cada trabajador y éste debería dar su consentimiento expreso. Sin consentimiento del trabajador, el acceso a sus comunicaciones solo debería permitirse de forma excepcional y requeriría de autorización judicial. Sin estas garantías, la empresa podría abusar de sus facultades de control y actuar como "un Gran hermano desconfiado al acceso de sus empleados, como si estos últimos hubieran vendido no solo su trabajo, sino también sus vidas personales a los empresarios".

16 Si una Sala del TEDH emite una sentencia contraria a los intereses de una parte se puede solicitar la remisión del asunto a ante la Gran Sala para una nueva consideración en base a lo establecido en el art. 43 del CEDH, que literalmente establece: "En el plazo de tres meses a partir de la fecha de la sentencia de una Sala, cualquier parte en el asunto podrá solicitar, en casos excepcionales, la remisión del asunto ante la Gran Sala”. 
sentencia estimando la pretensión del demandante el día 5 de septiembre de 2017. Al análisis de estos dos últimos pronunciamientos se dedican los apartados siguientes de este epígrafe.

\section{Antecedentes}

28. El demandante, ingeniero de ventas, a petición de su empresa creo una cuenta Yahoo Messenger (servicio de mensajería en línea que ofrece una transmisión de texto en tiempo real en internet) con el fin de recibir y responder preguntas de los clientes. Disponiendo dicho trabajador de otra cuenta Yahoo Messenger de uso personal.

29. Asimismo la empresa disponía, en cuanto al uso de la tecnología, de un reglamento interno que prohibía expresamente la utilización de estos recursos por parte de los empleados. Literalmente dicho reglamento establecía:

30. "Artículo 50: Está estrictamente prohibido perturbar el orden y la disciplina en el recinto de la empresa y particularmente ... usar los ordenadores, fotocopiadoras, teléfonos, el télex y la máquina de fax con fines personales".

31. Ha de resaltarse que este protocolo nada incluía, en cambio, en cuanto a la posibilidad del empresario de vigilar las comunicaciones de sus empleados. Siendo el demandante informado de dicho reglamento el día 20 de diciembre de 2006, cuya recepción así constaba firmada.

32. Posteriormente, el 3 de julio de 2007 la oficina donde desarrollaba sus funciones laborales el Sr. Barculescu procedió a distribuir, entre todos los empleados, una nota informativa cuyo contenido reiteraba lo ya establecido en el reglamento interno, y además comentaba literalmente:

33. "1. ... El tiempo que se pasa en la empresa debe ser tiempo de calidad para todo el mundo!!. Acudid al trabajo para ocuparos de los problemas de la empresa y profesionales, y no de los problemas privados!!. No paséis el tiempo en internet, hablando por teléfono o haciendo fotocopias de cuestiones que no competen a vuestro trabajo ni vuestras funciones. Estáis obligados a ello por (la educación elemental), el buen sentido y la ley!. La empresa se ve en la obligación de verificar y vigilar el trabajo de los empleados y de tomar las medidas oportunas contra los trabajadores en falta!.

2. ... Debido a las continuas faltas (de indisciplina cometidas) en contra de sus superior, (asi como) a la utilización que hizo de internet, del teléfono y de la fotocopiadora con fines privados, su negligencia e incumplimiento de sus funciones, la Sra. B.A. ha sido despedida por motivos disciplinarios! Tomad nota de este ejemplo negativo! No cometáis los mismos errores!"

34. Acto seguido, ente los días 5 y 13 de julio de 2007, la empresa registró en tiempo real las conversaciones del demandante en Yahoo Messenger. Este último día, en concreto, el Sr. Barbulescu fue convocado por su director. En dicha convocatoria se le informaba de que se habían supervisado sus conversaciones en Yahoo Messenger y que ciertos elementos indicaban que había utilizado internet con fines personales, omitiendo por tanto lo establecido en el reglamento interno. Además, se adjuntaban graficas que indicaban que su navegación por internet era superior a la del resto de compañeros, no siendo en este momento informado si la supervisión de sus comunicaciones también afectaba a su contenido.

35. Ese mismo día, el Sr. Barbulescu respondió a su director que sólo había utilizado el Yahoo Messenger con fines profesionales.

36. Seguidamente fue convocado por segunda vez, conteniendo ahora sí el documento de convocatoria la trascripción de las comunicaciones que el demandante había mantenido con su hermano y su novia, durante el periodo que sus conversaciones estuvieron sometidas a vigilancia, dichas comunicaciones trataban temas privados y algunas de ellas eran de carácter íntimo. 
37. El mismo 13 de julio el demandante informó por escrito que consideraba a la empresa responsable de la comisión de un delito, en concreto, la violación del secreto de correspondencia.

38. Todo culmina, por último, el 1 de agosto de 2007 cuando la empresa procede a rescindir el contrato de trabajo del Sr. Barbulescu.

39. Ante esta decisión, el trabajador insta la nulidad de su despido ante diversas instancias judiciales, basando su pretensión en la violación del art. 8 del CEDH. Tras ser inadmitida su pretensión recurre al TEDH por entender que los tribunales precedentes no habían tutelado correctamente sus derechos.

40. Finalmente inadmitida su pretensión de tutela de derechos, el trabajador demanda a Rumanía ante el TEDH por vulnerar el art. $8 \mathrm{CEDH}$ que consagra los derechos a la vida privada y a la correspondencia.

\section{Propuestas jurídicas de la primera de las STEDH}

41. Un aspecto que resulta coincidente en los razonamientos jurídicos de las dos sentencias emitidas por el TEDH sobre este asunto (12 de enero de 2016 y 5 de septiembre de 2017), es el comienzo de la valoración jurídica delimitando los términos del art. 8 del CEDH "vida privada" y "correspondencia".

42. En este sentido la Sentencia de 2016 considera útil recordar que la noción de "vida privada" es un concepto amplio que no se presta a una definición exhaustiva, incluyendo el derecho a establecer y desarrollar relaciones con otros seres humanos, y el derecho a la identidad y al desarrollo personal [SSTEDH de 16 de diciembre de 1992 (Caso Niemietz contra Alemania) y de 12 de junio de 2014 (Caso Fernández Martínez contra España)]. No obstante aclara el Tribunal que "interpretar el artículo 8 de forma amplia no significa que la protección se extienda a toda actividad en la que una persona quiera participar con otros seres humanos para establecer y desarrollar estas relaciones."(apartado 35).

43. Por lo tanto, según esta jurisprudencia tendrán cabida en los conceptos del citado artículo del Convenio, las comunicaciones telefónicas, la navegación por internet y hasta los correos electrónicos [SSTEDH de 25 de junio de 1997 (Caso Halford contra Reino Unido), 16 de febrero de 2000 (Caso Amman contra Suiza), y de 3 de abril de 2007 (Caso Copland contra Reino Unido)]. No obstante, añade la sentencia que habría que determinar si "a la vista de la prohibición general impuesta por el empleador, el demandante podía seguir razonablemente esperando que sus comunicaciones no serían vigiladas". Pero no se contiene respuesta a esta pregunta, limitándose el pronunciamiento a dejar constancia de que "los elementos incluidos en los autos no permiten dar a esta cuestión una respuesta clara y directa" a la vista de las discrepancias existentes entre las partes (apartados 36 y 42).

44. Acto seguido el Tribunal sitúa su reflexión en el marco de las obligaciones positivas que el art. $8 \mathrm{CEDH}$ atribuye a los Estados en orden a garantizar los derechos que ese precepto reconoce. Al respecto estima que la queja del demandante debe ser examinada desde esa perspectiva "puesto que era un empleado de una empresa privada, cuyas acciones no podían comprometer la responsabilidad del Estado en virtud del Convenio" (apartado 53). También manifiesta el TEDH que "el demandante tuvo la oportunidad de plantear, ante los tribunales nacionales, sus alegaciones según las cuales su empleador había vulnerado su derecho al respeto de la vida privada y correspondencia", y que "los tribunales nacionales examinaron debidamente los argumentos del demandante y estimaron que el empleador habia actuado en el contexto de las competencias disciplinarias que le otorgaba el Código de Trabajo" quedando, por tanto, establecido "que el demandante había cometido una infracción disciplinaria" (apartado 56).

45. En este contexto el Tribunal observa que las anteriores instancias otorgaron "particular importancia" al hecho de que el empleador había accedido a la cuenta Yahoo Messenger del demandante pensando que contendría mensajes de carácter profesional, puesto que el mismo demandante había 
afirmado inicialmente que había usado la cuenta para asesorar a sus clientes. Por lo tanto, se deduce "que el empleador actuó de conformidad con sus competencias disciplinarias puesto que, tal y como constataron los tribunales nacionales, accedió a la cuenta Yahoo Messenger basándose en el supuesto de que la información allí contenida estaba relacionada con actividades profesionales y que, por ende, acceder a ella era legítimo" (apartado 57).

46. En cuanto a la cuestión de las transcripciones de las comunicaciones, concluye que su uso fue adecuado, pues los tribunales nacionales se apoyaron en ellas "solamente en la medida que demostraban la infracción disciplinaria cometida por el demandante, esto es, que habia usado el ordenador de la empresa con fines personales durante horarios laborales", sin mencionar las circunstancias particulares en las que tuvieron lugar las comunicaciones, ni revelaban la identidad de las partes con las que se comunicaba el Sr. Barbulescu, ni cualquier otro dato o documento guardado en su ordenador (apartado 58 y 60).

47. A la vista de estas consideraciones, culmina su valoración jurídica el TEDH afirmando que no había elemento alguno en el presente asunto que indicase que las autoridades nacionales incumpliesen su obligación de establecer un equilibrio adecuado, entre los intereses del empleador y el derecho del demandante al respeto de su vida privada en virtud del art. 8 del CEDH (apartado 62).

48. Este criterio es, en definitiva y en líneas generales, el establecido hasta esta sentencia por la doctrina del Tribunal Constitucional y Supremo, las cuales admitían y justificaban el control empresarial de las comunicaciones realizadas por los trabajadores desde el ordenador de empresa cuando existiera una prohibición de uso con fines personales.

\section{Propuestas jurídicas de la segunda de las STEDH}

49. Como ya se comentaba en líneas precedentes, la sentencia del TEDH de 5 de septiembre de 2017, dictada por la Gran Sala, a diferencia de todas las instancias precedentes, procede a estimar la demanda interpuesta por el Sr. Barbulescu apreciando la violación del art. 8 del CEDH.

50. En su valoración jurídica el Tribunal comienza, en primer lugar, contextualizando la cuestión y recordando cuál era la postulación de la parte demandante y la conclusión de la Sala Cuarta. Posteriormente, repasa la jurisprudencia del TEDH en relación a la vida privada recordando que debe interpretarse en sentido amplio incluyendo el derecho a realizar una "vida privada social", es decir, la posibilidad de que el individuo desarrolle su identidad social, y que puede incluir tanto actividades profesionales, como aquellas que tengan lugar en un contexto público (apartado 70 y 71).

51. Asimismo continúa añadiendo que las comunicaciones que se emiten desde el puesto de trabajo, así como las del domicilio, pueden incluirse en las nociones de vida privada y correspondencia del art. 8 del CEDH (apartado 73).

52. Sin embargo, tras esta exposición de argumentos jurídicos y jurisprudenciales, la Gran Sala manifiesta en su apartado 77 "que el demandante había sido informado de la prohibición de uso de internet para fines personales establecida en las normas internas de la empresa empleadora (apartado 14). Pero continua añadiendo, y aquí viene la novedad, que "no está tan claro" que el Sr. Barbulescu "hubiera sido informado con antelación del alcance y naturaleza de la supervisión efectuada por su empleador o de la posibilidad de acceder al contenido de sus comunicaciones" (apartado 78). Ello conduce a la Gran Sala a considerar que el art. 8 del CEDH es aplicable al supuesto debatido (apartado 81).

53. Seguidamente el Tribunal pasa a reflexionar sobre las características que rodean las relaciones entre empresas y empleados, destacando su clara diferencia respecto del sistema general de relaciones entre individuos (apartado 116). Así, continua añadiendo que los "tribunales nacionales deben 
velar porque el establecimiento por una empresa de medidas para vigilar la correspondencia y otras comunicaciones, sea cual sea su alcance y duración, vaya acompañada de garantías adecuadas y suficientes contra los abusos" (apartado 119).

54. Por último, tras manifestar su consciencia en cuanto a los cambios que se están sucediendo en la sociedad como consecuencia de la llegada de las tecnologías a la vida social y profesional, considera que la proporcionalidad y las garantías procesales contra el carácter arbitrario son elementos esenciales. Exponiendo que las autoridades nacionales deberían tener en cuenta los siguientes factores (apartado 120):

55. PRIMERO.- Si el empleado ha sido informado de la posibilidad de que el empleador tome medidas para supervisar su correspondencia y otras comunicaciones, así como la aplicación de tales medidas. Para la Gran Sala, en principio, para que la medida pueda ser considerada conforme al art. 8 del Convenio, la advertencia debe ser "clara en cuanto a la naturaleza de la supervisión y antes del establecimiento de la misma".

56. SEGUNDO.- Alcance de la supervisión realizada por el empleador y el grado de intrusión en la vida privada del empleado. A este respecto la Gran Sala determina que "debe hacerse una distinción entre el control del flujo de comunicaciones y el de su contenido. También se debería tener en cuenta si la supervisión de las comunicaciones se ha realizado sobre la totalidad o sólo una parte de ellas y si ha sido o no limitada en el tiempo y el número de personas que han tenido acceso a sus resultados".

57. TERCERO.- La existencia o no de argumentos suficientes para el control. Afirmando la Gran Sala, que "dado que la vigilancia del contenido de las comunicaciones es por su naturaleza un método mucho más invasivo, requiere justificaciones más fundamentadas".

58. CUARTO.- Posibilidad de establecer un sistema de vigilancia basado en medios y medidas menos intrusivos que el acceso al contenido de las comunicaciones. En este sentido considera el Tribunal que "es necesario evaluar, en función de las circunstancias particulares de cada caso, si el objetivo perseguido por el empresario puede alcanzarse sin que éste tenga pleno y directo acceso al contenido de las comunicaciones del empleado".

59. QUINTO.- Consecuencias del control y uso por el empresario de los datos obtenidos, así como la adecuación de ese uso a la finalidad que legitima el control, y

60. SEXTO.- Garantías ofrecidas al trabajador. La sentencia aclara, en este punto, que "estas garantías debian impedir que el empleador tuviera acceso al contenido de las comunicaciones en cuestión sin que el empleado hubiera sido previamente notificado de tal eventualidad”.

61. Aplicando estos principios al caso concreto, el tribunal aprecio que, en efecto, había existido vulneración del art. 8 del CEDH (apartado 140). Ello por los siguientes motivos: En primer lugar, el Tribunal señala que los órganos jurisdiccionales nacionales no valoraron el hecho en cuanto que el demandado parece no hubiera sido informado con antelación del alcance y naturaleza del control efectuado por la empresa o de la posibilidad de que la empresa tuviera acceso al contenido de sus comunicaciones (apartado 132). Tampoco valoraron el alcance y carácter intrusivo del control, afirmando que el registro de las comunicaciones parece se realizó en tiempo real, y que el empresario tuvo acceso a ellas y que imprimió su contenido (apartado 133). Por otra parte, también alega la Gran Sala que los tribunales precedentes no examinaron suficientemente si el objetivo perseguido por el empleador podía haberse logrado mediante métodos menos intrusivos que el acceso al contenido mismo de las comunicaciones (apartado 135), ni se examinó la gravedad de las consecuencias de la medida de control y el procedimiento disciplinario que se siguió (apartado 136). Por último, el Tribunal observa que las autoridades nacionales no determinaron en que momento del procedimiento disciplinario el empresario tuvo acceso a dichos contenidos (apartado 137). 
62. Por todo ello, el TEDH consideró que los tribunales rumanos no protegieron adecuadamente el derecho del trabajador al respeto de su vida privada y de su correspondencia y que, por lo tanto, no valoraron el justo equilibrio entre los intereses en juego, produciéndose en consecuencia, una violación de las obligaciones positivas del Estado que derivan del art. 8 del CEDH.

\section{Conclusiones}

63. Matices coincidentes, y también dispares, presentan las sentencias emitidas por el TEDH en el caso Barculescu.

64. Comenzando por las similitudes, cabe destacar que ambos pronunciamientos parten en sus valoraciones jurídicas de la delimitación de los términos vida privada y confidencialidad del art. 8 $\mathrm{CEDH}$. Entendiendo que las comunicaciones telefónicas, la navegación por internet y los correos electrónicos tienen cabida en los conceptos del citado artículo, pues este debe entenderse en sentido amplio incluyendo el derecho a realizar una vida privada social.

65. Igualmente, ambos pronunciamientos prestan atención a la exigencia ya manifestada por nuestros tribunales referida a la necesidad de advertencia "clara y previa" sobre las instrucciones de uso de los recursos tecnológicos de la empresa por los trabajadores, y también de información "clara y previa" del establecimiento de medidas de vigilancia y control de los mismos.

66. Sin embargo, es en este aspecto donde comienzan a aparecer las discrepancias entre ambas sentencias. De modo, que mientras que Barbulescu 1 interpreta cumplida por la empresa ambas exigencias, deduciéndose que si el empresario informaba sobre la política de uso y control, la expectativa de confidencialidad desaparecía, por lo que no habría lesión del derecho a la intimidad, ni del secreto de las comunicaciones. Barbulescu 2 interpreta los hechos ocurridos y las pruebas aportadas por las partes de manera contraria, en el sentido de que no acepta (por no quedar constatado) que la empresa hubiera advertido al trabajador previamente sobre el control que iba a realizar, ni que el demandante, antes de llevar a cabo ese control, manifestara que sólo había realizado un uso profesional de los recursos tecnológicos de la empresa.

67. Este cambio de apreciación llevó al TEDH, en ese segundo pronunciamiento, a situarse más próximo a la línea jurídica expresada por las últimas sentencias del TS y TC, en el sentido de exigir la concurrencia de ciertos prepuestos jurídicos en aras a admitir una limitación de los derechos fundamentales del trabajador. En concreto fundamenta su argumento en los siguientes tres presupuestos:

- Advertencia clara y previa sobre las instrucciones de uso de los recursos tecnológicos de la empresa por los trabajadores, así como del establecimiento de medidas de vigilancia y control de los mismos.

- Sometimiento del control empresarial al triple juicio de la proporcionalidad, y

- La elección siempre de medidas menos intrusivas en la vida del trabajador.

68. Por todo ello, el TEDH considero en ese segundo pronunciamiento, en contraposición al primero, que no se habían protegido adecuadamente los derechos del art. $8 \mathrm{CEDH}^{17}$. Situándose, en consecuencia, en una postura más exigente al requerir no sólo la concurrencia de prohibición, sino también la advertencia de control, lo cual se debe de completar con la superación de la proporcionalidad. Todo esto viene, en definitiva, a elevar el listón de exigencia en materia de transparencia en la información previa, lo cual hace necesario su confrontación con los últimos planteamientos de nuestros tribunales españoles.

17 En este sentido J.L. GoÑ SEIN, «La vigilancia empresarial de las conversaciones electrónicas de los trabajadores», Trabajo y Derecho, núm. 18 (Sección Unión Europea y Agenda Internacional), 2016, p. 4, ya criticaba no haberse pronunciado el TEDH en tal sentido en la primera sentencia, toda vez, que la postura del primer pronunciamiento entrañaba "el riesgo de vaciar el derecho fundamental a la intimidad del trabajador en el contexto de las nuevas tecnologías, de un contenido aplicativo identificable". 


\section{EI más reciente de los pronunciamientos del TEDH en relación al control tecnológico del em- presario: Caso López Ribalda y otras contra España}

69. El pasado 9 de enero de 2018, el TEDH dictó otra sentencia sobre la materia de comentario en las actuaciones iniciadas por demandas 1874/2013 y 8567/2013 dirigidas contra España. El origen de la controversia se encuentra en la acción planteada por cinco cajeras (en adelante, trabajadoras o demandantes) de una cadena de supermercados despedidas disciplinariamente en el año 2009, tras constatarse la comisión de irregularidades laborales a través de cámaras de videovigilancia.

70. Esas demandas en primera instancia fueron desestimadas por considerarse que el uso de la videovigilancia encubierta en el lugar de trabajo sin una comunicación previa era conforme al art. 20 del ET, que permitía a un empresario la utilización de medidas de control y vigilancia que considerara adecuadas para verificar si un empleado/a estaba cumpliendo debidamente con sus tareas, guardando la correspondiente consideración debida a su dignidad.

71. Del mismo modo, añadía el Juzgado de lo Social No. 1 de Granollers, que en los casos donde existan fundadas sospechas de robos, las especiales circunstancias justifican la injerencia en el derecho del empleado a la privacidad, que es considerara como adecuada, necesaria y proporcionada al legítimo objetivo perseguido.

72. Por estos motivos este Juzgado, con base en la STC 186/2000, de 10 de julio (RTC 200/186) procedió a considerar evidente que el empresario tenía suficientes motivos para concluir que la conducta de las trabajadoras suponía una violación de la buena fe contractual y abuso de confianza de conformidad con el art. 54.2 del ET.

73. Acto seguido, las demandantes apelaron ante el TSJ de Cataluña que confirmo las dos sentencias de primera instancia, remitiéndose a la jurisprudencia del TC, y apoyando la conclusión del Juzgado de lo Social en cuanto que la empresa estaba autorizada a llevar a cabo una videovigilancia encubierta de las cajas registradoras. Aunque reconociendo que era posible que el empresario pudiera enfrentarse a una sanción administrativa por no informar a sus empleados y al comité de personal con carácter previo a la instalación de las cámaras.

74. Ante la inadmisión anterior de la pretensión, presentan recurso de casación ante el TS y amparo ante el TC, siendo inadmitidos ambos por considerarse inexistente la violación de un derecho fundamental.

75. Por último las trabajadoras recurren al TEDH, siendo atribuido el conocimiento del Recurso a la Sección Tercera, que declaró por unanimidad, salvo un voto, que la conducta empresarial había sido constitutiva de una violación del art. 8 del CEDH. Véase a continuación un análisis de esta última sentencia.

\section{Antecedentes}

76. Las demandantes son cinco trabajadoras españolas que en 2009 mantenían vinculación contractual con una cadena familiar de supermercados. A principios de febrero de ese año el empresario fue informado por el director del supermercado de ciertas incoherencias entre el nivel de stocks y las cifras cotidianas de ventas del establecimiento.

77. Con el fin de investigar y poner fin a dichas perdidas económicas, el 15 de junio de 2009 el empresario instaló cámaras de videovigilancia tanto visibles como ocultas. El propósito de las cámaras visibles era grabar posibles robos de los clientes y estaban colocadas en las entradas y salidas del supermercado. El propósito de las cámaras ocultas era grabar y controlar los posibles robos de los empleados 
y enfocaban a las cajas registradoras, cubriendo el área de detrás de la caja. La empresa comunicó a sus trabajadores previamente la instalación de las cámaras visibles, sin embargo, ni ellos ni el comité de personal de la empresa fueron informados de las cámaras ocultas.

78. Los días 25 y 29 de junio de 2009 todos los trabajadores sospechosos de robos fueron convocados a una reunión individual en la cual se le mostraron ciertos vídeos. Durante dichas reuniones las demandantes, en presencia del representante sindical y del representante legal de la empresa, admitieron su implicación en los robos.

79. Tres de las cinco demandantes firmaron un acuerdo por el cual reconocían su participación en los hurtos y renunciaban a accionar por despido ante los tribunales laborales, por su parte la empresa se comprometía a no promover la iniciación de un proceso penal contra ellas. Las otras dos demandantes no firmaron el acuerdo.

80. Finalmente todas las demandantes terminaron ejerciendo acciones, pero sus despidos fueron confirmados en primera instancia y después en suplicación, sin que fueran admitidos los recursos de casación y amparo. Recurriendo, por último, al TEDH por vulneración del art. 6 y 8 del CEDH.

\section{Valoración jurídica del Tribunal sobre el asunto}

81.Como se desprende del análisis de la sentencia comentada, la última de las resoluciones del TEDH sobre la materia gira sobre dos ejes vertebradores. El primero la vulneración del derecho a la vida privada (art. 8 del CEDH); y el segundo, la vulneración del derecho a un proceso justo (art. 6 del CEDH), sobre el que no entraremos a comentar por su irrelevancia en relación con el objeto de este comentario.

82.Analizando el primero de los ejes, el TEDH inicia su valoración recordando, igual que hacían las anteriores sentencias del caso Barbulescu, el sentido del mencionado artículo 8 del Convenio, señalando que "la videovigilancia encubierta de un empleado/a en su lugar de trabajo, debe ser considerada, [...] como una importante intromisión en su vida privada." Pues "Supone la documentación grabada y reproducible de la conducta de una persona en su lugar de trabajo, que él/ella no puede evitar al estar obligado/a por el contrato de trabajo a desempeñar su trabajo en dicho lugar" (apartado 59).

83.Seguidamente centra su reflexión en el marco de las obligaciones positivas que el citado artículo atribuye a los Estados, concluyendo que estas obligaciones "pueden implicar la adopción de medidas destinadas a respetar la vida privada incluso en el ámbito de las relaciones de los individuos entre sí" (apartado 60), debiendo, en consecuencia, valorar si en el marco de esas obligaciones el Estado "llevó a cabo una ponderación justa entre el derecho a la vida privada de las demandantes y el interés del empresario a la protección de sus poderes de organización y dirección, en relación con su derecho a la propiedad, así como el interés público en una correcta administración de justicia" (apartado 61).

84.En este contexto señala el Tribunal, en primer lugar, que la videovigilancia encubierta se llevó a efecto después de que el supervisor de la tienda detectara pérdidas, y se plantearan fundadas sospechas de la comisión de robos por parte de las demandadas, así como por otros empleados y clientes (apartado 62).

85.En segundo lugar, también observa que los datos visuales obtenidos implican el almacenamiento y procesamiento de datos de carácter personal, estrechamente vinculados a la esfera privada de los individuos. Este material fue consiguientemente procesado y examinado por diversas personas que trabajaban para el empresario (entre otros, el representante sindical y representante legal de la empresa) antes de que los recurrentes fueran informados de la existencia de esas grabaciones de video.

86.Sobre este aspecto concluirá el TEDH que la legislación vigente en el momento de los hechos contenía previsiones específicas de protección de datos de carácter personal. En efecto al amparo del 
art. 5 de la Ley 15/1999, de 13 de diciembre, de protección de datos de carácter personal (en adelante, LOPD), los demandantes tenían derecho a ser informadas "previamente de modo expreso, preciso e inequívoco" de "la existencia de un fichero o tratamiento de datos de carácter personal, de la finalidad de la recogida de éstos y de los destinatarios de la información; del carácter obligatorio o facultativo de su respuesta a las preguntas que les sean planteadas; de las consecuencias de la obtención de los datos o la negativa a siniestrarlos; la posibilidad de ejercitar los derechos de acceso, rectificación, cancelación y oposición; y de la identidad y dirección del responsable del tratamiento, o en su caso, de su representante" (apartado 64).

87. También recuerda el art. 3 de la Instrucción núm. 1/2006 de la Agencia Española de Protección de Datos, que impone esta obligación a cualquiera que use sistemas de videovigilancia, en cuyo caso, debe colocar un distintivo indicando las zonas que están bajo vigilancia, y confeccionar un documento disponible para los interesados que contenga la información prevista en el art. 5 de la LOPD (apartado 65).

88. El Tribunal subraya, como reconocieron los tribunales españoles, que "el empresario de las demandantes no cumplió con la obligación de informar a las interesadas de la existencia de medios de recogida y tratamiento de sus datos personales, según lo prescrito en la ya mencionada legislación interna". Además de esto, observa que el propio Gobierno español reconoció específicamente que los trabajadores nunca fueron informados de la instalación de videovigilancia oculta enfocada sobre las cajas, ni de sus derechos conforme a la LOPD.

89. A pesar de ello los Tribunales españoles, consideraron que la medida fue justificada (por existir indicios razonables de hurto); idónea para conseguir el fin propuesto, necesaria y proporcionada, desde el momento que no había otras medidas igualmente efectivas para proteger los derechos del empresario que interfirieran menos con el derecho de las demandantes al respeto de su vida privada.

90. En este punto el TEDH distingue en presente caso de la situación examinada en el Caso Köpke. De hecho, comenta "en ese caso, en el tiempo en que el empresario llevó a efecto la videovigilancia encubierta tras las sospechas de robo contra dos empleadas, todavía no se habían establecido en el estatuto condiciones en que un empresario podía utilizar la videovigilancia de un empleado para investigar un delito [...]. Sin embargo, en el presente asunto la legislación en vigor en el momento de los hechos de la causa establecía claramente que todo recolector de datos debia informar a los sujetos de la recogida de datos, de la existencia de medios de recogida y tratamiento de sus datos de carácter personal" (apartado 67).

91. Asimismo, continua añadiendo, se diferencian en que en Köpke la medida de vigilancia estuvo limitada en el tiempo (se llevó a cabo durante dos semanas), y sólo dos empleados fueron el objeto de la medida. Lo que no ocurre en el caso comentado, donde la medida se dirigía a todo el personal que trabajaba en las cajas registradoras, durante semanas, sin límite de tiempo y durante todas las horas de trabajo.

92. En consecuencia no comparte la opinión de los tribunales nacionales sobre la proporcionalidad de la medida adoptada por el empresario con el objetivo legítimo de proteger interés del empresario. Entendiendo, que "la videovigilancia llevada a cabo por el empresario, que se prolongó durante un largo periodo de tiempo, no cumplía con los requisitos establecidos en el artículo 5 de la Ley de Protección de Datos de Carácter Personal y, en particular, con la obligación mencionada anteriormente de informar previamente a los interesados de modo expreso, preciso e inequivoco sobre la existencia y características particulares de un sistema de recogida de datos de carácter personal" (apartado 69). En este sentido, los derechos del empresario podían haber sido protegidos por otros medios, en especial, informando previamente a las demandantes, incluso de una manera general sobre la instalación de dicho sistema y dotándolos de la información establecida en la LOPD. 
93. Concluyendo, finalmente que los tribunales internos no ponderaron un justo equilibrio entre el derecho de las demandantes al respeto de su vida próvida conforme al art. 8 del CEDH y el interés del empresario en la protección de sus derechos propietarios (apartado 70).

\section{Conclusiones}

94. Poco difiere, de los anteriores pronunciamientos comentados, la siguiente y última de las STEDH en materia de empleo de medios tecnológicos en la empresa como medio de prestación y control laboral. Tanto es así, que en este caso el Tribunal vuelve a reiterar el guion argumentativo de Barculescu, con la única salvedad de que detiene especial atención a lo dispuesto en la normativa vigente en España en cuanto a la protección de datos, la cual resulta aplicable desde el momento que se tienen acceso con los controles a datos personales de los trabajadores.

95. Comenzando por la proporcionalidad, el TEDH reitera el contenido de dicho juicio con apoyo en tres sentencias fundamentales del TC, en concreto, las Sentencias 186/2000, de 10 de julio (RTC 2000/186), 29/2013, de 11 de febrero (RTC 2013/29) y 39/2016, de 3 de marzo (RTC 2016/39).

96. A continuación, aquí la diferencia con Barbulescu, detiene la atención en la normativa sobre protección de datos, afirmando "no será suficiente que el tratamiento de datos resulte en principio lícito, ... o que pueda resultar eventualmente, en el caso concreto de que se trate, proporcionado al fin perseguido; el control empresarial por esa vía, antes bien, aunque podrá producirse, deberá asegurar también la debida información previa” de acuerdo con lo establecido en el art. 5 LOPD.

97. Y finalmente concluye de conformidad con los anteriores criterios, y aquí apreciamos el posible avance, o quizás nueva conjugación que propone la STEDH López Ribalda, que una medida de vigilancia y control podrá ser absolutamente proporcional, pero si previamente no se ha procedido a cumplir con el trámite de información previa a los interesados de modo expreso, preciso e inequívoco sobre la existencia y características particulares del sistema de recogida de datos, la conducta empresarial será considerada como "una importante intromisión" en la vida privada de los trabajadores (apartado 59).

98. Con ello parece querer decirnos el TEDH, que sólo cuando se haya cumplido con el deber de información, podrá continuarse con la valoración de la proporcionalidad, y sólo cuando ambos presupuestos se cumplan (información y proporcionalidad) estaremos ante una medida legitima de control respetuosa con los derechos fundamentales de los trabajadores.

\section{Transcendencia interna de las recientes sentencias}

99. Escasos han sido los pronunciamientos del TS y TSJ que han sucedido a las anteriores sentencias comentadas, siendo sólo dos los que entran a valorar y confrontar la doctrina judicial española existente hasta la fecha con la reciente del TEDH.

100. Respecto a las propuestas interpretativas de Barbulescu, el TS en sentencia de 8 de febrero de 2018 (Rec. 1121/2015) resulta claro y breve en la valoración de los efectos que podría desplegar sobre la jurisprudencia española, afirmando que "tales consideraciones del Tribunal Europeo nada sustancial añaden a la doctrina tradicional de esta propia Sala [...] y a la expuesta por el Tribunal Constitucional en la sentencia de contraste [...], pues sin lugar a dudas los factores que acabamos de relatar y que para el TEDH deben tenerse en cuenta en la obligada ponderación de intereses, creemos que se reconducen básicamente a los tres sucesivos juicios de «idoneidad», «necesidad»y «proporcionalidad» requeridos por el TC y a los que nos hemos referido en el FD Quinto [5.b)]."

101. En cuanto a López Ribalda y su planteamiento sobre el deber de información del art. 5 LOPD, nada afirmará el citado Tribunal debiendo de estarse a los posibles comentarios y valoraciones 
que pueda manifestar en las sucesivas sentencias. Máxime teniendo en cuenta la reciente entrada en vigor del Reglamento 2016/679 relativo a la protección de las personas físicas en lo que respecta al tratamiento de datos personales y de cuyo ámbito de aplicación personal y material no quedan excluidas las relaciones laborales ${ }^{18}$, el cual viene a contribuir al interés de garantizar una mayor protección de los derechos y libertades tanto de los ciudadanos como de los trabajadores.

102. Si lo hará, en cambio, el TSJ de Castilla-La Mancha en su sentencia el 12 de enero de 2018 (Rec. 1416/2017). Considerando que mientras Barbulescu en nada altera los términos interpretativos de la doctrina española sobre la materia, si influirá este último pronunciamiento en la próxima jurisprudencia del TS, que venía aplicando la última doctrina constitucional sentada por la STC 39/2016, de 3 de marzo (RTC 2016/39), la cual no consideraba necesario el consentimiento expreso del trabajador para el tratamiento de las imágenes obtenidas a través de las cámaras instaladas en la empresa con el fin de seguridad o control laboral, considerándolo una medida conforme al art. 20.3 ET ${ }^{19}$.

103. Con este panorama incierto e inestable, donde unas veces se exige la información, en otras ocasiones el consentimiento o en otras el mero cumplimiento de la proporcionalidad, lo único irrefutable desde el punto de vista de lo razonable es que los trabajadores tienen que ser informados de las zonas videovigiladas y que también es legítimo y valido la instalación de cámaras de video cuando existan sospechas de incumplimientos laborales. Observándose en ambos casos la proporcionalidad.

104. Estas ideas serán las que plantea el TEDH en su reciente sentencia de 9 de enero de 2018, que vuelve a colocar el criterio interpretativo a seguir en la línea de la STC 29/2013, de 11 de febrero (RTC 2013/29) [que precedía a la sentencia 39/2016] que en síntesis establecía las mismas exigencias para considerar legitima la vigilancia y control, que la última de las sentencias del TEDH.

105. Llegados a este punto no puede hacerse nada más que esperar a los próximos pronunciamientos del TS y TC, y observar de conformidad con lo establecido por el TEDH, cual es el criterio que regirá la resolución de las reclamaciones y recursos planteados ante las distintas instancias judiciales españolas.

106. No sin olvidar como acertadamente expresa PreCiado DomĖNECH ${ }^{20}$ la imperiosa necesidad que existe de establecer una legislación orgánica sobre las limitaciones de los derechos fundamentales de los trabajadores en el ámbito de la relación laboral, fundamentalmente por su interactuación con los poderes empresariales, pues es evidente que el art. 20.3 ET se manifiesta en la actualidad ciertamente obsoleto en cuanto a la articulación de los controles empresariales y derechos de los trabajadores. Al mismo tiempo añade García GonZález y García GonZALEZ ${ }^{21}$, que sin perjuicio de esa necesario intervención legislativa, la negociación colectiva también deberá actualizar y establecer qué usos irregulares facultan al empresario para proceder al despido disciplinario del trabajador y cuáles otros constituyen infracciones graves o leves, merecedoras de castigos menos severos.

18 Un análisis más detenido del mismo puede consultarse en J.L. GoÑ SeIn, «Nuevas Tecnologías Digitales, Poderes Empresariales y Derechos de los Trabajadores: Análisis desde la Perspectiva del Reglamento Europeo de Protección de Datos de 2016», Revista de Derecho Social, núm. 78, 2017, p. 15 y ss.

19 Reiterada en SSTS de 31 de enero 2017 (Rec. 3331/2015), 1 de febrero de 2017 (Rec. 3262/2015) y 2 de febrero de 2017 (Rec. 554/2016).

20 C.H. Preciado Domènech, «Comentario de urgencia a la SETDH de 9 de enero de 2018. Caso López Ribalta y otras c. España», Revista de Información Laboral, núm. 1, 2018, p. 10.

21 R. García González y J. Pastor Merchante, «Límites a la necesaria flexibilización de los derechos a la intimidad y al secreto de las comunicaciones en el ámbito laboral: una reflexión tras la sentencia del TEDH de 12 de enero de 2016 en el caso Barbulescu», Diario La Ley, núm. 8715 (Sección Tribuna), 2016, p. 5. 